\title{
Exploring the Feasibility of Text Messaging Intervention in Intimate Partner Violence
}

\author{
Rose Constantino', Linden $\mathrm{Wu}^{1}$, Dominique de la Cruz'1, Joseph Burroughs ${ }^{1}$, \\ JuHae Grace Hwang 1 , Amanda Henderson ${ }^{2}$, Betty Braxter ${ }^{3}$ \\ ${ }^{1}$ Department of Health and Community Systems, University of Pittsburgh School of Nursing, Pittsburgh, USA \\ ${ }^{2}$ UPMC Shadyside Emergency Department, University of Pittsburgh School of Nursing, Pittsburgh, USA \\ ${ }^{3}$ Department of Health Promotion and Development, University of Pittsburgh School of Nursing, Pittsburgh, \\ USA \\ Email: rco100@pitt.edu, liw39@pitt.edu, dominiquedelacruz@gmail.com, jdb109@pitt.edu, juh35@pitt.edu, \\ hendersonar@upmc.edu, bjbst32@pitt.edu
}

Received 23 April 2014; revised 3 May 2014; accepted 12 June 2014

Copyright (C) 2014 by authors and Scientific Research Publishing Inc.

This work is licensed under the Creative Commons Attribution International License (CC BY). http://creativecommons.org/licenses/by/4.0/

(c) †) Open Access

\section{Abstract}

Introduction: Intimate Partner Violence (IPV) is defined as controlling, abusive, and aggressive behavior in a romantic relationship. Women between the ages 16 and 24 experience the highest rate of IPV. IPV costs US society at least $\$ 13.6$ billion annually and is expected to rise to $\$ 15.6$ billion by 2021. The purpose of this study is to explore the feasibility of Text Messaging Intervention (TMI) in recognizing, responding and preventing IPV among college students. The research questions are: Will TMI 1) improve participant knowledge of warning signs of IPV? (Knowledge) and 2) improve participant confidence to intervene in IPV? (Confidence). Methods: A mixed methods design in data collection and data analysis was used. One-way ANOVA and Chi-square test were used to analyze quantitative data from the pre and post TMI survey. Results of the qualitative data analysis are included verbatim. Results: Results showed that knowledge level pre to post test increased from $2.00 \pm 1.00$ to $2.7 \pm 0.48(\mathrm{p}<0.001)$ and confidence level pre to post test increased from $2.89 \pm 0.60$ to $3.30 \pm 0.68(\mathrm{p}<0.001)$. Conclusions: Further research is needed in evaluating the feasibility and effectiveness of IPV prevention programs that uses mobile devices to create the best optimal health outcomes.

\section{Keywords}

Disruptive Innovations (DI), Intimate Partner Violence (IPV), Primary Prevention Strategy, Text Messaging Intervention (TMI), Violence Prevention 


\section{Introduction}

The research was initiated by the students who are recipients of Council for Undergraduate Research scholarships through the Undergraduate Research Mentoring Program (URMP). They were interested in helping other students recognize and prevent signs of Intimate Partner Violence (IPV) in their student life. University students are at high risk for IPV because of the newly gained freedom. Intimate relationships in a college campus have potential for IPV to unwary college students [1] [2]. College campuses have provided pamphlets and brochures to inform students of resources however students suggest moving away from the pamphlet as a source of information on IPV to using multiple mechanisms and mobile devices in preventing violence such as text messaging and other online resources [3].

Intimate Partner Violence (IPV) is defined as a pattern of repeated actual or threatened acts that physically, sexually, or verbally abuse of a significant other [1]. IPV is preventable but if left unabridged or unresolved, psychosocial consequences are possible and could become a precursor to intimate partner violence [2]. Women between the ages of 16 and 24 experience the highest rate of intimate partner violence-almost triple the national average [4]. In the 2010 National Intimate Partner \& Sexual Violence Survey found that $35.6 \%$ and $28.5 \%$ of men experience rape, physical violence or stalking by an intimate partner in their lifetime [5]. IPV costs U.S. society at least $\$ 13.6$ billion annually and is expected to rise to $\$ 15.6$ billion by 2021 [2] [6].

Research links occurrence and severity of multiple symptoms with impairments in functioning and quality of life in survivors of IPV. In the US, survivors of IPV lose a total of nearly 8 million days of paid work, the equivalent of more than 32,000 full time jobs and nearly 5.6 million days of household productivity each year. More than a third of female homicides globally are perpetrated by an intimate partner [7] [8]. The consequences of IPV are physical and mental health conditions including physical injury, chronic pain, headaches, sleeping or awakening problems, anxiety, depression, posttraumatic stress disorder, among others [9]. Furthermore, IPV presents increased risk of homelessness, lack of social support, unemployment, substance use, and suicidality [7] [10] [11].

The purpose of this study was to explore the usability and feasibility of Text Messaging as an intervention in preventing IPV among college students. Our specific aim was to evaluate text messaging as an effective method of delivering intervention on building healthy relationships and preventing intimate partner violence. The two research questions are: Will TMI 1) increase participant satisfaction (Satisfaction) and 2) increase participant confidence in their knowledge of IPV (Confidence).

\section{Review of the Literature}

IPV is associated with harmful health consequences that include: poor academic achievement, binge drinking, suicidal attempts, physical injury, and potential death. IPV is also linked to low self-esteem, anxiety, engagement of high risk sexual behavior and increased use of harmful substances (e.g. cigarettes \& alcohol) [1]. Half of youth who have been victims of both dating violence and rape attempt suicide compared to $12.5 \%$ of nonabused women and 5.4\% of non-abused men [8]. Being physically or sexually abused makes women six times more likely to become pregnant and twice as likely to get a STI [5]. The National Intimate Partner and Sexual Violence Survey (NISVS) reports that perpetrator are using birth control sabotage to control their victims and purposefully making them pregnant in the hope that having a baby will make the victim stay more reliant in the relationship and preventing them from escaping [5].

In a systematic review [12], text messaging was found to promote adherence in people living with HIV. Text-messaging interventions yielded significantly higher adherence than control conditions (OR = 1.39; 95\% $\mathrm{CI}=1.18,1.64)$. Sensitivity analyses of intervention characteristics suggested that studies had larger effects when text messages 1) were sent less frequently than daily, 2) supported bidirectional communication, 3) included personalized message content, and 4) were matched to participants' antiretroviral therapy dosing schedule. Interventions were also associated with improved viral load and/or CD4+ count $(k=3$; OR $=1.56$; 95\% CI $=1.11,2.20$ ). The authors suggested less frequent messaging interventions with content and timing that is individually tailored and designed to evoke a reply from the recipient. The text messages that are short, supports bidirectional personalized communication, and rhymed evoke positive response [13] [14].

We searched PubMed from January 1, 2005 to January 13, 2014 for studies comparing IPV interventions delivered via online or mobile devices such as e-mail, text messaging or social networking to interventions delivered via traditional means, e.g., face-to-face. Our search string utilized both Medical Subject Headings (MeSH) and keywords for the concepts of "intimate partner violence" and "technology". We identified two studies that 
evaluated the delivery of interventions via videoconferencing [15] [16]. We found no reported study on the use of mobile technology in delivering intervention for IPV survivors. In addition, we identified two survey studies [17] [18], that assessed preferences for, and use of, email among women who had experienced IPV. One study reported that email-mediated interaction with women and children who had received Protection from Abuse court orders was a feasible method of maintaining contact with this group citing our study [19].

Hassija et al. [15] tested the effectiveness and feasibility of videoconferencing technology in the treatment of 15 female rural domestic violence and sexual assault survivors and found large reductions on measures of PTSD and depression and participant satisfaction with video-conferencing. Tschirch et al. [16] used tele-mental health intervention to provide mental health services to address the unmet mental health needs of survivors of domestic violence who did not meet the admission criteria of a local women's shelter, requiring a diagnosis of major depression, bipolar illness, or schizophrenia, and a score of $<50$ in the Global Assessment of Functioning Scale. Results showed tele-mental health would help address the unmet needs of survivors of domestic violence.

Gilroy et al. [17] assessed which method of communication was preferred by 292 women experiencing abuse. The choices of communication were: phone voice, face-to-face, texting, email, or Facebook. The women in the sample preferred face-to-face and phone voice communication; however, many were open to texting, email or Facebook. Rothman et al. [18] explored the prevalence of email use among 57 female residents of a women's shelter. Results showed $47 \%$ had a current email account, $89 \%$ used email in locations other than their own homes, $81 \%$ reported that their email accounts had not been accessed by unauthorized intimate partners and $88 \%$ reported it would be safe for the shelter to email them following their discharge. Finally, in our own study [19] as cited by Rothman et al., email interaction was useful in providing information, screening, safety instructions, and follow-up care among female survivors of intimate partner violence, their teen-age child and the nurse interventionist.

A meta-analysis of 19 randomized controlled trials conducted in 13 countries that explored the efficacy of text messaging-based health promotion interventions was done by Head et al. [20]. The overall weighted mean effect size representing the impact of the interventions on health outcomes was $\mathrm{d}=0.329$ (95\% CI $=0.274,0.385 ; \mathrm{p}<$ 0.001). This effect size was statistically heterogeneous $\left(\mathrm{Q}_{18}=55.60, I^{2}=67.62\right)$, and several variables significantly moderated the effects of interventions for smoking cessation and physical activity. Text messaging-based interventions for smoking cessation and physical activity were more successful than interventions targeting other health outcomes. Text message tailoring and personalization were significantly associated with greater intervention efficacy [20].

\section{Methods}

A mixed methods design was used to examine the feasibility of text messaging as a tool for delivering intervention in IPV [21] [22]. Mixed methods design was used because quantitative or qualitative data collection and data analysis by itself may be inadequate in assessing whether TMI will improve participants' willingness to intervene in IPV situations, increase participant satisfaction, and increase participant confidence in their knowledge of IPV [21]-[24].

Before data collection, we responded to Creswell's five attributes in designing mixed methods studies, they are: 1) Rationale: Our rationale for mixing methods was to allow participants to respond to objective questionnaires with self-report answers, respond to subjective open ended questions, and/or share with the research team their thoughts, feelings, and ideas about their IPV experience unencumbered by filling-in or checking space limitations, 2) Data collection and data analysis paradigm: We used phenomenology as a mixed methods paradigm to integrate not only specific quantitative and qualitative data collection and analysis procedures but also the social construction of multiple phenomena understood as valid realities in the mind of the participant, 3) Priority: We gave priority to quantitative data collection and analysis by first collecting and analyzing quantitative data. Qualitative data collection and analysis came second, 4) Concurrent or sequential implementation: We used a sequential implementation and integration plan for data collection and data analysis techniques, and 5) Phase at which time mixing methods were done. Mixing of data collection and data analysis was planned at the proposal stage of the research and implementation occurred first at the data collection phase (combining objective items with subjective open-ended items in one questionnaire) and continued to the data analysis phase.

This research is guided by the theoretical framework of Disruptive Innovations (DI) [25]-[28]. A DI is the function of an intentionally and deliberately developed product or service, here, Text Messaging Intervention (TMI). DI as a fundamental paradigm takes a unique and bold approach to change the way information or inter- 
vention is communicated. DI does not focus on persuading individuals to change their behavior, attitude, or habit. Instead, it considers change as the evolution or the reshaping of products and behaviors to achieve greater fits to serve the needs of individuals, groups, and communities. In DI, individuals do not change but, innovation reshapes individual behaviors [28].

Text Messaging Intervention TMI is designed as a simple product that disrupts and diffuses a common activity (texting) and offers an inexpensive, simple, convenient service that has the potential for preventing or decreasing the risk of being in an IPV. Furthermore, TMI also informs participants of strategies to build healthy intimate relationships through research to a level that proximately reaches its users/consumers [10] [19]. TMI offers an inexpensive and convenient service that has the potential to be diffused as a disruptive tool in preventing or stopping IPV. TMI also informs the user/participant of strategies and resources to build healthy intimate relationships. As a disruptive innovation tool, it is diffused and received by a diverse population at a level that meets the needs of universal, selective and indicated users/consumers [1] [27] [28].

Ten male and ten female $(n=20)$ participants between 18 and 24 years old were recruited for this study. Recruitment was accomplished by posting flyers (see Figure 1) on bulletin boards of a private university in Southwestern Pennsylvania. To allow for a $20 \%$ attrition rate, 24 participants were recruited which gave us 20 participants between 18 and 24 years old who own and use mobile phone for texting and have access to the Internet. Participants were not screened whether they are experiencing IPV or not. We recruited them as diverse users of a product or service (TMI) inserted in the most common and simple activity that has the potential to disrupt and reshape their way of relating to others. Our inclusion criteria were 1) male and female undergraduate students, 2) between ages 18 and 24 years, 3) owns a smart phone, 4) uses text messaging communication system, and 5) is willing and able to sign an informed consent. No exclusion criteria were stated.

\title{
Announcement
}

\begin{abstract}
The University of Pittsburgh School of Nursing is seeking volunteers for a research study that explores the usability and readability of text messaging in building healthy dating relationships. Relationship violence is prevalent among college students, but many times students do not know the warning signs. Text messaging is one of the most common modes of communication used by young people. The purpose of this study is to explore text messaging as a method of sharing information on healthy dating relationships. Participants will be part of a 4 week study and receive multiple text messages each week, containing information about relationship violence. Participants must be 18-25 years old and currently using text messaging. If interested in participating, please contact Dr. Constantino at rco100@pitt.edu, Dominique Dela Cruz at dad78@pitt.edu, or Joseph Burroughs at jdb109@pitt.edu.
\end{abstract}
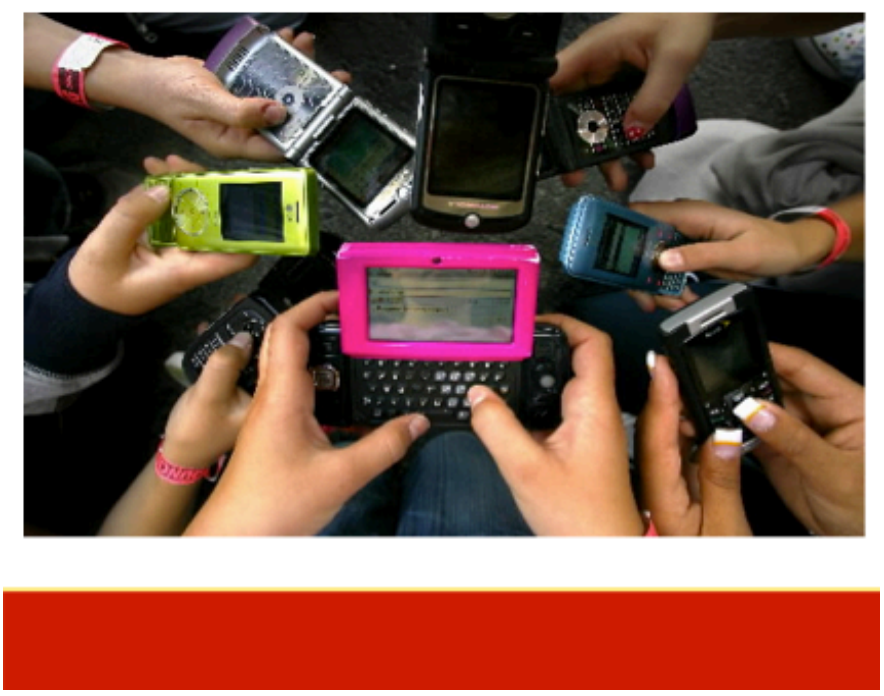

Figure 1. Flyer for recruitment. 
Due to the pilot exploratory nature of this study, the statistical power necessary to be generated by the small sample size (20) is difficult to determine. Furthermore, preliminary data with an effect size using the pre- and post TMI survey is not available. Determining the necessary effect size is one purpose of this pilot study. This pilot will give us data about recruitment and retention in the time period of the proposed study. A sample size of 20 produces a two-sided 95\% confidence interval with a distance from the mean to the limits that is equal to 0.47 when the estimated standard deviation is 1.00 and interval with a width equal to 0.05 when the sample proportion is 0.05. Twenty researcher-developed Text Messages comprise the TMI shown in Figure 2 and were delivered to 20 male and female college students once a day for four weeks after signing the Institutional Review Board-approved consent form. The 20 text messages were numbered $1-20$ and the first 5 text messages (items 1 - 5) were sent one day at a time during the first week followed by items 6 - 10 on the second week, 11 15 and $16-20$ on the third and fourth weeks respectively.

Data was collected twice, at baseline (Pre-TMI) (Figure 3) and week six (Post-TMI) (Figure 4) face-to-face. Participants received one TMI every day five-days-a-week for four weeks. The Pre and Post TMI Surveys were completed by participants. The survey sought quantitative and qualitative responses before and after four weeks of receiving Text Message Intervention (TMI) to assess the effects of TMI on awareness of potential violent behaviors, knowledge of the warning signs of IPV, and knowledge of actions to take to prevent IPV.

The use of mixed methods design allowed the research team to examine qualitative and quantitative data on the effects of TMI. The qualitative portion of the TMI includes the user's satisfaction with access, user-friendliness, convenience, practicality, and presence of distracting or unwanted words. Survey questions that we include in the analysis: 1) Satisfaction: Do you believe text messaging is an effective method of building healthy dating relationship why or why not. This item had a yes no response option and 2) Confidence: How confident do you feel w/your knowledge of warnings sings of dating violence and actions you can take to prevent it? This item used a four point Likert scale 1 = not at all confident, $2=$ neutral, $3=$ somewhat confident and 4 = very confident. One-way ANOVA, Chi-square test or other nonparametric statistical procedures was used to analyze quantitative data from the pre and post TMI survey.

\section{Results}

Twenty students, 10 males and 10 females completed the pre and post TMI survey. $70 \%$ of the participants owned a smart phone and $80 \%$ have used a cell phone for the past 5 years. $50 \%$ of the participants used texting as

1. When on a date, agree on a place that's public and in view.

2. Hear nicknames making you feel worthless let them know they are tactless.

3. If your partner is always in your face, calmly say that you need some space.

4. Healthy dating relationships grow from mutual respect and fairness.

5. When out on a date, watch your partner's manner. If degrading, could be the wrong partner.

6. Don't jump into a romance because it's the trend.

7. Get to know the person you date and make sure there's mutual respect.

8. If your partner hurts you, do not allow it to continue.

9. If your partner hurts you, ask for help or tell a friend.

10. “Who are you with?” “Why aren't you calling?” Sound familiar? This is appalling.

11. Roses are red, violets are blue. Dating is sweet but should not leave marks on you.

12. Has your partner yelled because you are late? Watch out! This can only escalate.

13. Does your partner choose the clothes you wear? Caution! Deciding for you is unfair.

14. Choose three phone numbers you "trust", numbers you can dial fast.

15. Put your closest friends on fast dial so you can get them speedy style.

16. If in front of friends you are called names, think what you'll be called when no one's present.

17. Going on a date is like a plane ride, know the nearest exit and slide.

18. Family values are important don't abandon them to keep a partner.

19. When to see each other, what to do, and where to go should be decided by both of you.

20. Concerned for your safety? Move to an area where witnesses are plenty.

Figure 2. Text messages for the TMI research project. 
Before participating in this study, please take the time to fill out this survey regarding your cell phone usage and knowledge of intimate partner violence. All information will be kept strictly confidential.

1. Age:

2. Gender:

3. How long have you been using a cell phone?

Less than a year

1 - 2 years

3 - 5 years

More than 5 years

4. Do you own a smart phone?

Yes

5. Rank your preference from 1 to 5 for communicating with others when using your cell phone

Phone call
Text messaging
E-mail
Social media networks (Facebook, Twitter, MySpace, etc.)
Skype/Facetime

6. How frequently do you text?

Every hour
A few times a day
A few times a week
A few times a month
Rarely

7. How often do you check your inbox and respond to the sender of the text?

Always
Most of the time
Occasionally
Never

8. How confident do you feel with your knowledge of warning signs of dating violence and actions you can take to prevent it?

Very confident
Somewhat confident
Neutral
Not at all confident

9. How likely would you intervene if you had a friend in dating violence?

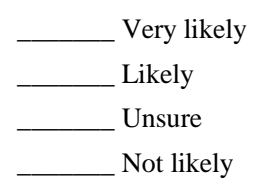

10. Which of the following would you FIRST do if you saw a friend involved in dating violence?

Talk to your friend
Confront your friend's violent partner
Ask another friend or family member for advice
Nothing
Other (please list):

11. Please list the signs of dating violence:

Thank you for participating in our study!

Figure 3. Pre TMI survey. 
Please respond to the following questions.

1. Were the text messages readable and easy to understand? Please describe why or why not.

2. Was text messaging an effective method of dating violence education? Please describe why or why not.

3. How confident do you feel with your knowledge of warning signs of dating violence?

Very confident

Somewhat confident

Neutral

Not at all confident

4. How confident do you feel with your knowledge of actions that you can take to prevent it?

Very confident

Somewhat confident

Neutral

Not at all confident

5. How likely would you intervene by using text messages if you had a friend involved in dating violence? Very likely

Likely

Unsure Not likely

6. Would you use any of these text messages if you were experiencing any type of dating violence? Yes No

7. Would you send any of these text messages to a friend experiencing relationship violence? Yes No

8. Which of the text messages were most interesting?

9. Which of the text messages were least interesting?

10. Please create your own text message for building healthy dating relationships.

11. Please list any other comments or suggestions.

Thank you for participating in our study!

\section{Figure 4. Post TMI survey.}

their first mode of communication. 90\% reported to texting every hour. In both the pretest and posttest, 10 students said they would use text messages as a form of intervention. Results showed that knowledge level pre to post test scores increased from $2.00 \pm 1.00$ to $2.7 \pm 0.48(\mathrm{p}<0.001)$ and confidence level pre to post test scores increased from $2.89 \pm 0.60$ to $3.30 \pm 0.68$ ( $\mathrm{p}<0.001)$. In the pretest 12 students were somewhat confident and four participants were very confident about their knowledge about IPV warning signs and actions taken to prevent IPV. In the post test 12 students were somewhat confident and 4 students became very confident to intervene in IPV.

In our qualitative analysis, the participants commented that they liked how the "text messages were readable and easy to understand because they were short and direct”. They had no problems comprehending the message the researchers were trying to convey via TMI. Four participants stated the TMI is an effective tool because "since the messages were sent to their phone they were forced to read them". Another participant stated "I feel 
text messages are one of those things you're forced to read (as opposed to emails, fliers, presentations etc.). Texts are the new means of communication, so it is an appropriate method of IPV education”. An overarching theme why the participants thought the TMI is an effective tool is that the text messages were catchy and rhymed.

\section{Discussion}

The research question asked whether there was a difference before and after TMI in study participants as measured by the TMI survey was answered positively through the acceptance of the hypothesis that stated there was a significant difference in study participants before and after TMI. This study could serve as a catalyst for developing intervention and educational programs that support, inform, and educate college students of the consequences of IPV and evidence-based strategies to prevent it [2] [25]-[30].

Results of this pilot project may provide important data on the importance of early and timely information to college students on building healthy relationships and strategies to prevent IPV even before they enter into such relationships. Text messaging has been used in helping young adults understand sexual health promotion [12] [13]. A text messaging intervention (TMI) was developed to assess the effects of TMI on awareness of potential IPV behaviors, knowledge of the warning signs of IPV, and knowledge of actions to take to prevent IPV.

This study supports Gold's and others [13] in a randomized controlled trial using mobile advertising to promote safe sex and sun safety to young people. As commented in our results and supported by Gold and others, TMI could be an effective tool when the text messages are short, catchy and rhymed. Replication of this study using a larger sample size, more follow-up assessments and using a wait-list control is needed to confirm our findings that TMI improves participants’ willingness to intervene in IPV situation, increases participant satisfaction and increases participant confidence in their knowledge of IPV.

This study has a number of limitations. First the small sample size prohibits generalization. Second there was no follow up after the post test survey. Third and lastly analysis of the qualitative data could have been done simultaneously and included in this report. Despite these limitations, results of this study contribute to our understanding of the need to evaluate the use of mobile technology in IPV interventions. There is a great need to triangulate quantitative with qualitative outcomes by quantifying qualitative data and/or qualifying quantitative data to complete the picture of the lived experience of recognizing and responding to prevent intimate partner violence in young adults.

\section{Acknowledgments}

The authors would like to express their appreciation to the University Of Pittsburgh School Of Nursing Undergraduate Research Mentorship Program for providing the resources for this project. The support of NCUR, URMP, and the Department of Health and Community Systems of the University of Pittsburgh School of Nursing is acknowledged.

\section{References}

[1] Centers for Disease Control and Prevention (2009) National Youth Risk Behavior Survey Overview. http://www.cdc.gov/HealthyYouth/vrbs/pdf/us_overview_yrbs.pdf

[2] Centers for Disease Control and Prevention (2012) Dating Matters: Strategies to Promote Healthy Teen Relationships. http://www.cdc.gov/ViolencePrevention/pdf/DatingMatters_flyer.pdf

[3] Garcia, C.M., Lechner, K.E., Frerich, E.A., Lust, K.A. and Eisenberg, M.E. (2012) Preventing Sexual Violence Instead of Just Responding to It: Students' Perceptions of Sexual Violence Resources on Campus. Journal of Forensic Nursing, 8, 61-71. http://dx.doi.org/10.1111/j.1939-3938.2011.01130.x

[4] Claiborne, Liz Inc. (2012) Love Is Not Abuse: http://loveisnotabuse.com/web/guest/college_introduction

[5] National Center for Injury Prevention and Control \& Centers for Disease Control and Prevention: Division of Violence Prevention (2011) The National Intimate Partner and Sexual Violence Survey: 2010 Summary Report. http://www.cdc.gov/ViolencePrevention/pdf/NISVS Report2010-a.pdf

[6] Black, M.C., Basile, K.C., Breiding, M.J., Smith, S.G., Walters, M.L., Merrick, M.T., Chen, J. and Stevens, M.R. (2011) The National Intimate Partner and Sexual Violence Survey: 2010 Summary Report. National Center for Injury Prevention and Control Division of Violence Prevention.

[7] Stockl, H., Davies, K., Rotstein, A., Abrahams, N., Campbell, J. and Garcia-Moreno, C. (2013) The Global Prevalence 
of Intimate Partner Homicide: A Systematic Review, Lancet, 382, 859-865. http://dx.doi.org/10.1016/S0140-6736(13)61030-2

[8] Tjaden, P. (2005) Defining and Measuring Violence against Women: Background, Issues, and Recommendations. Statistical Journal of the United Nations, 22, 217-234.

[9] Montalvo-Liendo, N., Wardell, D.W., Engebretson, J. and Reininger, B.M. (2009) Factors Influencing Disclosures of Abuse by Women of Mexican Descent. Journal of Nursing Scholarship, 41, 359-367. http://dx.doi.org/10.1111/j.1547-5069.2009.01304.x

[10] Campbell, J.C. (2002) Safety Planning Based on Lethality Assessment for Partners for Partners of Batterers in Treatment. Journal of Aggression, Maltreatment and Trauma, 5, 129-143. http://dx.doi.org/10.1300/J146v05n02_08

[11] Kimerling, R., et al. (2007) The Veterans Health Administration and Military Sexual Trauma. American Journal of Public Health, 97, 2160-166. http://dx.doi.org/10.2105/AJPH.2006.092999

[12] Finitsis, D.J., Pellowski, J.A. and Johnson, B.T. (2014) Text Message Intervention Designs to Promote Adherence to Antiretroviral Therapy (ART): A Meta-Analysis of Randomized Controlled Trials. PLoS One, 9, Article ID: e88166. http://dx.doi.org/10.1371/journal.pone.0088166

[13] Gold, J., Aitken, C.K., Dixon, H.G., Lim, M.S., Gouillou, M., Spelman, T., Wakefield, M. and Hellard, M.E. (2011) A Randomized Controlled Trial Using Mobile Advertising to Promote Safer Sex and Sun Safety to Young People. Health Education Research, 26, 782-794. http://dx.doi.org/10.1093/her/cyr020

[14] Heron, K.E. and Smyth, J.M. (2010) Ecological Momentary Interventions: Incorporating Mobile Technology into Psychosocial and Health Behavior Treatments. British Journal of Health Psychology, 15, 1-39. http://dx.doi.org/10.1348/135910709X466063

[15] Hassija, C. and Gray, M.J. (2011) The Effectiveness and Feasibility of Videoconferencing Technology to Provide Evidence-Based Treatment to Rural Domestic Violence and Sexual Assault Populations. Telemedicine and E-Health, 17, 309-315.

[16] Tschirch, P., Walker, G. and Calvacca, L.T. (2006) Nursing in Tele-Mental Health. Journal of Psychosocial Nursing and Mental Health Services, 44, 20-27.

[17] Gilroy, H., McFarlane, J., Nava, A. and Maddoux, J. (2013) Preferred Communication Method of Abused Women. Public Health Nursing, 30, 402-408. http://dx.doi.org/10.1111/phn.12030

[18] Rothman, E., Meade, J. and Decker, M.R. (2009) E-Mail Use among a Sample of Intimate Partner Violence Shelter Residents. Violence against Women, 15, 736-744. http://dx.doi.org/10.1177/1077801209332188

[19] Constantino, R.E., Crane, P.A., Noll, B.S., Doswell, W.M. and Braxter, B. (2007) Exploring the Feasibility of EmailMediated Interaction in Survivors of Abuse. Journal of Psychiatric and Mental Health Nursing, 14, 291-301. http://dx.doi.org/10.1111/j.1365-2850.2007.01080.x

[20] Head, K.J., Noar, S.M., Iannarino, N.T. and Harrington, N.G. (2013) Efficacy of Text Messaging-Based Interventions for Health Promotion: A Meta-Analysis. Social Science \& Medicine, 97, 41-48. http://dx.doi.org/10.1016/j.socscimed.2013.08.003

[21] Creswell, J.W., Klassen, A.C., Clark, V.L.P. and Smith, K.C. for the Office of Behavioral and Social Sciences Research, NIH (2011) Best Practices for Mixed Methods Research in the Health Sciences.

http://obssr.od.nih.gov/mixed_methods_research/pdf/Best_Practices_for_Mixed_Methods_Research.pdf

[22] Constantino, R.E. (2007) A Transdisciplinary Team Acting on Evidence through Analysis of Moot Malpractice Cases. Dimensions of Critical Care Nursing, 26, 150-155. http://dx.doi.org/10.1097/01.DCC.0000278766.39348.04

[23] Johnson, R.B. and Onwuegbuzie, A.J. (2004) Mixed Methods Research: A Research Paradigm Whose Time Has Come. Educational Researcher, 33, 14-26. http://dx.doi.org/10.3102/0013189X033007014

[24] Plano Clark, V.L. and Wang, S.C. (2011) Adapting Mixed Methods Research to Multicultural Counseling. In: Creswell, J.W., Klassen, A.C., Plano Clark, V.L. and Smith, K.C., Eds., Best Practices for Mixed Methods Research in the Health Sciences.

http://obssr.od.nih.gov/mixed_methods_research/pdf/Best_Practices_for_Mixed_Methods_Research.pdf

[25] Ponterotto, J.G., Matthew, J.T. and Raughley, B. (2013) The Value of Mixed Methods Designs to Social Justice Research in Counseling and Psychology. Journal of Social Action in Counseling and Psychology, 5, 42-68.

[26] Miller, E. and Levenson, R. (2013) Hanging out or Hooking up: Clinical Guidelines on Responding to Adolescent Relationship Abuse. Futures without Violence.

[27] Fisher, J. and Clayton, M. (2012) Who Gives a Tweet: Assessing Patients' Interest in the Use of Social Media for Health Care. Worldviews on Evidence-Based Nursing, 2nd Quarter, 9, 100-108.

[28] Robinson, L. (2009) A Summary of Diffusion of Innovations. http://www.enablingchange.com.au/Summary Diffusion Theory.pdf 
[29] Constantino, R.E. and Privitera, M.R. (2011) Prevention Terminology: Primary, Secondary, Tertiary, and an Evolution of Terms. In: Privitera, M.R., Ed., Workplace Violence, Jones and Barlett Publishers, Suddbury.

[30] Gordon, R. (1983) An Operational Classification of Disease Prevention. Public Health Reports, 98, 107-109. 
Scientific Research Publishing (SCIRP) is one of the largest Open Access journal publishers. It is currently publishing more than 200 open access, online, peer-reviewed journals covering a wide range of academic disciplines. SCIRP serves the worldwide academic communities and contributes to the progress and application of science with its publication.

Other selected journals from SCIRP are listed as below. Submit your manuscript to us via either submit@scirp.org or Online Submission Portal.
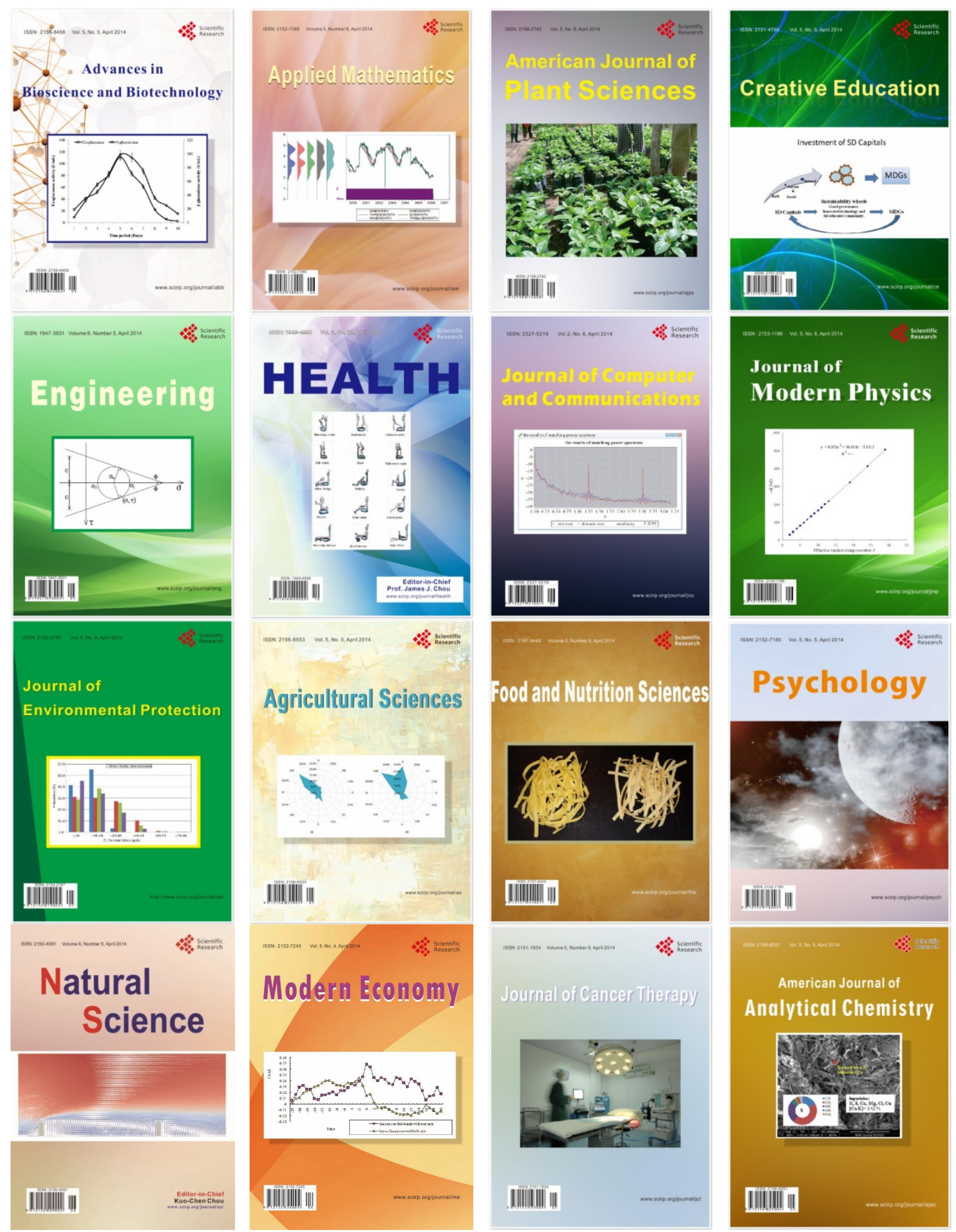